\title{
On the new paradigm of personality in mining education
}

\author{
Andrew Zykov ${ }^{*}, 1$, Anastasia Demeneva ${ }^{1}$, Michal Cehlár ${ }^{2}$, and Juraj Janočko \\ ${ }^{1}$ T.F. Gorbachev Kuzbass State Technical University, Science and Innovation Department, 650000 \\ Kemerovo, 28 Vesennyaya st., Russian Federation \\ ${ }^{2}$ Technical University in Kosice, Faculty of Mining, Ecology, Process Control and Geotechnologies, \\ Letná 9, 04200 Kosice, Slovak Republic
}

\begin{abstract}
In today's information storm, conventionally speaking, we can distinguish two types of information: the $1^{\text {st }}$ is "Hypertext" or Big Text this is a huge array of structured and unstructured information. System comprehension of hypertext in the chosen field is a classical school, secondary or higher professional education; the $2^{\text {nd }}$ is compactified knowledge, i.e. the result of the knowledge approach. Compactified knowledge is presented in a special, "condensed" form, including extensive use of infographics and other visual techniques. They can also be organized in such a way as to operate with human actions (algorithms). To a scientist, the use of compactified knowledge allows him to see better and faster the interconnections of the subject of his research with other disciplines. This is especially necessary for interdisciplinary, breakthrough research. Compactified knowledge includes, for example, checklists, which summarize to one or two pages the experience of incorrect actions in a certain situation, making it possible to avoid them. Compactification does not replace the experience of long-term learning with "hypertext", it complements the experience of conventional education in those situations where "quick" knowledge is needed for application and where the cost of error is high. Without basic education, the effect of applying compactified knowledge may be lower. Compactified knowledge is not impoverished (reduced) knowledge, but condensed, concentrated knowledge. It is obvious that in the field of knowledge compactification demand exceeds supply, techniques and methods of its generation are in a state of formation, and generators of this knowledge are obviously not enough, which opens a wide field of activity in this direction.
\end{abstract}

\section{Introduction}

Based on the principles of rational and formal logic, as well as the philosophy and history of natural science [1-7], we describe and analyze the possibilities of new approaches to technical education, united by the fact that they change both the methodology of educational activities in technical fields, and its subject area to increase efficiency [8-13].

*Corresponding author: zykovav@,kuzstu.ru 
By this we mean, if to formulate a thesis, the following:

1) desire of enterprises to obtain not only knowledgeable, but also able specialists;

2) a new need for an integral specialist who can easily switch between the work required by the enterprise and independent creative activity in non-standard and uncertain situations;

3 ) the ability to build new ways and algorithms of activity independently and in contact with the community and to complete the existing ones, if necessary, using new possibilities of communication and information society;

4) Closely related to item 3 is the multi-disciplinary nature that is so necessary for a technician who must henceforth have an understanding not only of related professions but also of the humanities;

5) we will also point out the link between points 3 and 4. A specialist needs humanitarian knowledge in order to be able to "condense" (concentrate) vast and diverse information very effectively, making it accurate, accessible and understandable not only to himself, but also to his colleagues and subordinates (in order to avoid dangerous situations for any enterprise: what can be understood incorrectly will certainly be understood incorrectly);

6) Skills of thinking and body orientation in the technogenic environment of the enterprise and workplace. Simulators are widely used for training, for example, pilots, excavator operators, etc., that is, to train a specialist in a very narrow, specific direction - a kind of "mono-simulator", subject to the relation "1 operator -1 machine". The question arises - why it is impossible to create something similar for training engineers and technicians, considering as a simulator the very environment of the enterprise - macro- (or multi-) simulator?

7) Unofficial "culture" of the enterprise and informal relations within the collective as instruments of efficiency.

\section{Materials}

Let's try to present all the above as the following semantic blocks:

"Knowledge is power, and the ability of a person to turn knowledge into skills and abilities is the management and multiplication of power".

Skills cannot be attributed to the field of knowledge, although the boundary between one and the other is often difficult to draw [14-18]. Let us consider their differences and relations between them. Knowledge, if it is deeply assimilated, is a kind of material from which a special unit - a control action (CA) - can be built (or not built). A controlling action is understood not only as an action of a manager of any level, but also as any action that a specialist performs at an enterprise. It can be both intellectual and physical action (management of one's own body in the production environment for the purpose of performing work operations) [19-22].

Knowledge is a resource used to build a control action. Without knowledge, no CA is possible. However, this resource also has an operator. It is the personality of the human himself, features of his intellect and mental organization. A person, in the entirety of its properties and qualities, processes knowledge, integrating this resource through the perception and actions of the human body with the environment and the situation in which the CA is carried out, and then, if the operation is regular, gradually translates it into an automatic or semi-automatic mode [23-24].

Thus, it is personality properties that determine the speed and quality of translation of knowledge into skills and abilities.

Without belittling the values of knowledge, without which the activity of any specialist is impossible, let's say that exactly those key personality traits that allow to translate 
knowledge into skills and abilities are the core of specialist training. Exactly they define the specialist's value for the enterprise in the key way, because knowledge without skills is passively in the memory and therefore cannot be demanded and applied, whereas in the presence of certain personal qualities the lack of knowledge can be easily compensated.

Let us conclude: the process of training a demanded specialist is impossible without acquiring by a person those qualities that allow him/her to transfer knowledge into skills and abilities and to make up for the lack of knowledge if necessary [26-28].

Therefore, we need to find out what these qualities and exactly how they are acquired.

\section{Results}

"How to "technician" become "humanitarian" and for what".

When reading scientific books of a century or more ago, many people pay attention to the fact that they are written in some particularly clear and understandable language. Evidence of this is far from isolated, and so they do not just get away with it. A preliminary analysis of the texts and the historical context in which they were created makes it possible to formulate the following hypotheses:

1. Clarity, simplicity, depth and conciseness of texts are conditioned by a serious humanitarian training of their authors in terms of classical education.

2. A private but very significant manifestation of paragraph 1 is that the authors of these texts in the course of the educational process studied deeply not only philosophy in general, but also, in particular, such its most important field as logic (art of thought) and rhetoric (art of words).

Let us try to understand exactly how this can affect the quality of texts.

Qualitative humanitarian (classical) education forms, first of all, the personality of a person at the deepest level. A. Einstein (and V. Heisenberg later) spoke about it this way: "Education is what remains when everything we have learned is forgotten. Education, if you will, is a bright glow that envelops our memories of school years and illuminates our entire subsequent life. It is not only the brilliance of youth, naturally inherent in those times, but also the light that comes from doing something significant".

According to them, classical education forms "the ability to turn any problem into a fundamental one". "Whoever is engaged in the philosophy of the Greeks, at every step comes across this ability to raise fundamental questions, and, therefore, reading the Greeks, he exercises the ability to possess one of the most powerful intellectual tools developed by Western European thought".

But what exactly is left when we forget everything?

This is the art of clear, precise and deep thought.

F. Nietzsche wrote: "The school has no more important task to teach strict thinking, caution in judgment, and consistency in reasoning... The importance of gymnasium is rarely seen in the things that it really learns and that are taken out of there forever, but in those that are taught but that a student learns only with disgust to shake them off as soon as it is possible.

Thus, the things that are "learned there" are the abilities to think and apply. This is exactly what the classical humanitarian school gave its students.

Clouded, burdened with a lot of unnecessary details and branches, a thought cannot be clear, which means that it cannot be understood by those it is transmitted to. Conversely, a clear and imaginative thought is understandable to everyone.

And here it is worth remembering that in pre-revolutionary Russia, classical education was an integral stage of the educational process for both humanitarian and technical specialists. After passing the gymnasium (classical) school, it remained forever the property 
of the individual and was actively used in the work - even if the specific knowledge given by the gymnasium was gradually lost for lack of need.

But there is also another aspect of this question, besides the clarity of logic and thinking.

Humanitarian Classical education provides its adherents with a huge set of metaphors and images from literature and art, which they can now use to teach others in a variety of fields, and which are a great addition to the precise and vivid thought, using eidetic features of human perception.

The combination of precision (clarity) of thought and eideticism (figurativeness) makes the text so clear and easy to digest.

From this it becomes clear a very important drawback of modern trajectories of technical education: they renounce the classical humanitarian culture too early, in fact already at the secondary school level.

It is fair to say that the humanitarian component of secondary school itself is far from the practice of classical education and suffers from one-sidedness and oddness, which does not contribute to the growth of interest in it among those who have a propensity for exact and technical sciences.

As a result, a person who wants to get a technical education, in most cases, unconsciously perceives the stamps of superiority of "physicists" over "lyrics" that still exist in the minds of technical intellectuals, or appear in practice, without even knowing what "lyricists" have treasures for their own personal development, including as specialists. In the conditions of even implicit repressions against all classical education and philosophy, technical education becomes one-sided and in many respects mute, poorly adapted to transmission.

In this situation, it is the higher technical school, committed to the principles of efficiency, can try to correct the situation and implement the turnaround, creating new standards and practices of the educational process in its own and in contact with industry, which will not only increase the level of demand for its graduates and improve the quality of enterprises, but will develop, even in the first iteration, the genre requirements for the training of a neo-engineer. Maybe it is arguably damp and requires adjustment, but there is something here.

So, what will these new practices consist of? Here it is possible, at first glance, a paradoxical synthesis of classical culture, in its best traditions and samples, which develop the thinking and creative properties of the individual, on the one hand, and tools, channels of output of the trained specialist to the immediate needs of enterprises, on the other hand with full or partial immersion in the environment and culture of the enterprise with new, acquired opportunities for learning, creativity and adaptation. This, we expect, will have a major synergy effect on the new type of education.

Wherein, the university's tasks are as follows:

1. Harmonious installation of a compact but effective and rich classical educational module into a technical education program.

2. Creation of special, informal channels of communication between the enterprises and technical university, thanks to which the newly acquired skills (p.1) can be used at the levels of "personality, thought, body".

3. Creation of effective educational forms for a new type of education, capable of combining points 1 and 2 in the educational process.

The programme of such learning will be mobile, constantly developing. 


\section{Conclusions}

Let's see which directions may be presented:

\section{The creative and humanitarian module}

The art of precise and clear thought. Logic and dialectics. Features of creation, transmission and perception of images and metaphors. The art of transferring knowledge and information. The practice of condensing knowledge, perception, application and translation of condensed knowledge.

\section{Position and orientation flexibility of a new specialist}

It is about training a specialist who is able to quickly navigate in a changing environment and working surroundings, using the personal qualities obtained in the process of education, as well as move, if necessary, to adjacent and close to the profile of the activity positions without affecting the work. Such skills are also necessary for professional empathy - the ability to put oneself in the shoes of another specialist (a colleague, a partner, an employee of another division, etc.) to understand his problems and needs. This improves communication and interaction at the enterprise level as a whole.

\section{How and why should an engineer and technician become a philosopher}

Philosophy and human culture can teach not only clarity of thought. One of the properties of philosophy is the creation of life values. The modern world and divergent ideas almost always impose the value of a vertical career on a person. However, the number of leadership positions is limited a priori, and a company needs people in all positions. With the help of this philosophy, you can realize the value of horizontal professional development, without the desire to climb higher at any cost, because it is no less interesting to be the self-leader, or self-director, and move forward, but from technicians and engineers not in the director, but in super-technicians and super-engineers. In this case, in life makes special sense and disappears nervousness. By the way, such a specialist has a stronger chance of real career growth than the one who feverishly rushes to the top by any means.

\section{References}

1. W. Whewell, History of the inductive sciences: from the earliest to the present times (J.W. Parker, London, 1837)

2. W.S. Jevons, Elementary Lessons in Logic: Deductive and Inductive. With Copious Questions and Examples and a Vocabulary of Logical Terms (Macmillan and Co, London, 1870)

3. H. Spencer, Illustrations of universal progress: a series of discussions (D. Appleton, New York, 1877)

4. T. Carlyle, Past and present (Chapman and Hall, London, 1843)

5. J. Priestley, An essay on a course of liberal education for civil and active life (C. Henderson, Strand, 1765)

6. J.S. Mill, A System of Logic, Ratiocinative and Inductive, Being a connected view of the Principles of Evidence, and the Methods of Scientific Investigation (Harper \& Brothers Publishers, New York, 1881)

7. P. Lavrov, Historical Letters (California Press, Berkeley, Los Angeles, 1967)

8. O. Litvin, M. Tyulenev, S. Zhironkin, S. Prokopenko, Acta Montanistica Slovaca, 22(2), 146 (2017)

9. M. Tyulenev, S. Markov, M. Cehlar, S. Zhironkin, M. Gasanov, Acta Montanistica Slovaca, 23(4), 368 (2018) 
10. A. Ključnikov, M. Civelek, V. Krajčík, I. Ondrejmišková, Acta Montanistica Slovaca, 25(2), 224 (2020)

11. A. Katsubin, S. Markov, A. Khoreshok, M. Tyulenev, E3S Web of Conf., 174, 01027 (2020)

12. A. Strelnikov, S. Markov, L. Rattmann, D. Weber, E3S Web of Conf., 41, 01003 (2018)

13. R. V. Klyuev, I. I. Bosikov, A. V. Mayer, O. A. Gavrina, Sustainable development of mountain territories, 12(2), 283 (2020)

14. S. Markov, Ju. Janočko, M. Tyulenev, Ya. O. Litvin, E3S Web of Conf., 105, 01021 (2019)

15. T. Gvozdkova, S. Markov, N. Demirel, S. Anyona, E3S Web of Conf., 21, 01024 (2017)

16. A. V. Katsubin, A. A. Khoreshok, M. A. Tyulenev, S. O. Markov, Mining Inf. Anal. Bull., 2020(11), 27 (2020)

17. M. A. Tyulenev, S. O. Markov, M. A. Gasanov, S. A. Zhironkin, Geotech Geol Eng, 36(5), 2789 (2018

18. S. Markov, M. Tyulenev, O. Litvin, E. Tyuleneva, E3S Web of Conf., 15, 01011 (2017)

19. Yu. Lesin, V. Gogolin, E. Murko, S. Markov, Ju. Kretschmann, E3S Web of Conf., 41, 01039 (2018)

20. M. Tyulenev, A. Khoreshok, E. Garina, O. Litvin, Y. Litvin, E. Maliukhina, IOP Conference Series: Earth and Environmental Science, 50(1), 012035 (2017)

21. T. Gvozdkova, E. Kuznetsov, A. Rudakova, S. Markov, E3S Web of Conf., 15, 01008 (2017)

22. M. Tyulenev, S. Markov, E. Makridin, Yu. Lesin, V. Gogolin, E3S Web of Conf., 105, 02022 (2019)

23. P. Habek, W. Bialyand, G. Livenskaya, Acta Montanistica Slovaca, 24(1), 25 (2019)

24. S. Markov, V. Martyanov, E. Preis, A. Abay, E3S Web of Conf., 21, 01021 (2017) 